\title{
Salmonella typhimurium Mutations Conferring Resistance to Felix $O$ Phage without Loss of Smooth Character: Phage Attachment and Immuno- chemical and Structural Analyses of Lipopolysaccharides
}

\author{
By A. A. LINDBERG* \\ Department of Medical Microbiology, Stanford University School of Medicine, \\ Stanford, California 94305, U.S.A. \\ AND S. SVENSSON \\ Department of Organic Chemistry, Stockholm University, Stockholm, Sweden
}

(Received 24 April 1974; revised 29 July 1974)

\begin{abstract}
SUMMAR Y
Salmonella typhimurium mutants, called Felix O-resistant (FOR), selected for resistance to phage Felix $\mathrm{O}(\mathrm{FO})$ which has its receptor in the core lipopolysaccharide (LPS), retain most of the properties of the smooth parent strain (MacPhee, Krishnapillai, Roantree \& Stocker, I975). LPS extracted from one parent and two FOR strains by the phenol-water and the phenol-chloroform-light petroleum methods have been subjected to passive haemagglutination inhibition and methylation analysis. The amount of LPS, the amount of O-specific sugars in the LPS, and the average length of the $O$ chains were almost the same in parent and mutant strains. Neither passive haemagglutination nor methylation analysis revealed the presence of incomplete cores in the mutant strains. Determinations of the rates of attachment of $\mathrm{P}_{22}$ (receptor in $\mathrm{O}$ chain) and FO phages to whole bacteria of the same strains also suggested there is as much O-chain material in the FOR strains as in the parent strain. The data suggest that the FOR strains are the result of a mutation in the synthesis of the core, leaving few, if any, completed cores accessible to the FO phage.
\end{abstract}

\section{INTRODUCTION}

MacPhee et al. (I975) describe Salmonella typhimurium mutants which are resistant to Felix $\mathrm{O}$ (FO) phage but display a smooth character (FOR mutants). When tested for cultural and serological properties and for phage sensitivity, the mutants were shown to retain all or nearly all the characters of smooth strains. The genetic analysis showed, however, that in all mutants tested the FOR mutations were situated in the $c y s E-p y r E$ region of the linkage map. This short segment contains nearly all of the identified $r f a$ loci concerned in the biosynthesis of the core of the lipopolysaccharide (LPS) (Stocker \& Mäkelä, I97I).

The complete core of Salmonella LPS constitutes the receptor for the FO phage (Lindberg, 1973) (Fig. I). Mutants of Salmonella lacking only the terminal non-reducing $N$-acetylglucosamine (branch) residue of the core are resistant to the FO phage, and this amino sugar is therefore supposed to be an essential part of the receptor. Mutants of FOR strains, tentatively identified as class $r f c$ and presumed to be deficient in the polymerization of the $\mathrm{O}$

* Present address: National Bacteriological Laboratory, Stockholm, Sweden. 
repeating units and thus to have a side-chain of one repeating unit only, are FO sensitive (MacPhee et al. 1975). It is inferred from this that the receptor for the FO phage is still synthesized in FOR strains but that access to it is hindered. Two kinds of LPS change might cause this effect: (i) the accessibility of the receptor to the phage might be reduced by the presence of longer $\mathrm{O}$ side-chains in the FOR strains than in the parent strain; (ii) FO sensitivity in smooth strains might be due to the presence in their LPS of complete core chains, not capped by $\mathrm{O}$ chains and so available to the phage. A mutation in core biosynthesis in FOR strains might then result in few complete core chains being synthesized so that all (or nearly all) of them would be covered by $\mathrm{O}$ chains leaving none (or few) available to the FO phage.

We have investigated FOR mutants and LPS extracted from them by passive haemagglutination inhibition and methylation analysis. The results show that: (i) FOR strains contain, on a weight basis, as much LPS as the parent strain; (ii) the average number of repeating units per $O$ chain is the same in FOR mutants as in the parent strain; and (iii) passive haemagglutination inhibition and methylation analysis did not reveal the presence of incomplete cores in the FOR strains or in the parent strain.

\section{METHODS}

Bacterial strains. All strains used came from the collection of Dr B. A. D. Stocker, Department of Medical Microbiology, Stanford University. A description of the strains is given by MacPhee et al. (I975). Each strain was re-isolated from a single colony and tested for nutritional characteristics and phage sensitivity. For extraction of LPS the bacteria were grown and harvested as described by Lindberg \& Holme (I972). LPS was extracted by either the hot phenol-water (PhW) procedure (Westphal \& Jann, 1965) or the aqueous phenolchloroform-light petroleum (PCP) procedure (Galanos, Lüderitz \& Westphal, 1969).

Antisera. Antisera against Salmonella $\mathrm{O}$ antigens 4,5 and $\mathrm{I}_{2}$ were prepared in rabbits ( 2 to $2.5 \mathrm{~kg}$ ) of both sexes. The strains used for immunization were according to Kauffmann (1966). Three to five animals were used for each antigen. For immunization, heat-killed bacteria $\left(100{ }^{\circ} \mathrm{C}, 2 \mathrm{~h}\right)$ suspended in phosphate buffered saline $(\mathrm{pH} \mathrm{7.3)}$ to a concentration of approximately $\mathrm{IO}^{10}$ bacteria $/ \mathrm{ml}$ were used. The animals were given intravenous injections on days $\mathrm{I}, 6$ and $\mathrm{I} 2(0.25,0.50$ and $\mathrm{I} \cdot 0 \mathrm{ml}$, respectively). They were exsanguinated on day 17 , and sera pooled. All serum pools were absorbed with heat-killed bacteria of heterologous strains to render them specific for respective $O$ antigens (Kauffmann, I966). Antisera against the various classes of rough mutants (Fig. I) were prepared according to Lindberg \& Holme (1968).

Antisera against bacteriophage $\mathrm{P} 22 \cdot c 2$ and $\mathrm{FO}$ were prepared in rabbits by intravenous injection of $\mathrm{I} \cdot \mathrm{O} \times \mathrm{IO}^{11}$ plaque-forming units (p.f.u.) twice a week for three weeks. The rabbits were exsanguinated one week later and the sera pooled. None of the pooled sera gave a positive agglutination with the bacterial strain used for bacteriophage multiplication in a dilution of $\mathrm{I}$ : IO. The velocity constant $(K)$ for neutralization of the phages was $\mathrm{I} 68 \mathrm{~min}^{-1}$ for P22.c2 and $323 \mathrm{~min}^{-1}$ for EO.

Passive haemagglutination inhibition. The immunochemical specificity of the LPS preparations was studied by passive haemagglutination inhibition. The procedure was as described by Lindberg \& Holme (I 968). The antisera were diluted to 4 to 8 haemagglutinating units. The LPS:homologous-antiserum haemagglutination systems represented various classes of rough mutants as well as the $\mathrm{O}$ antigenic specificities of the smooth ancestor $S$. typhimurium $\mathrm{LT}_{2}\left(\mathrm{O}_{4}, \mathrm{O}_{5}, \mathrm{O}_{2} 2_{2}\right)$. 
Bacteriophages. The bacteriophages used consisted of the smooth-specific phage $\mathrm{P}_{22} . c 2$, the smooth- or rough-active $\mathrm{FO}$ phage, and the rough-specific phages $6 \mathrm{SR}, \mathrm{Br} 2, \mathrm{C} 2 \mathrm{I}, \mathrm{Ffm}$, $\mathrm{Br} 60$ and $\mathrm{P} 22 \mathrm{I}$. The relevant characteristics of the phages were recently described by Wilkinson, Gemski \& Stocker (1972).

The attachment rate constants (a.r.c.) for $\mathrm{P} 22 . c 2$ and FO were estimated by determination of (i) irreversible attachment, and (ii) number of phage-infected bacteria, i.e. infective centres unaffected by anti-phage serum. The bacteria were grown in nutrient broth, centrifuged and washed in tris- $\mathrm{HCl}$ buffer $(0.0 \mathrm{I} \mathrm{M}, \mathrm{pH} 7.2)$ supplemented with $0 . \mathrm{I} \mathrm{M}-\mathrm{NaCl}$ and finally suspended in the $\mathrm{NaCl}$-supplemented tris- $\mathrm{HCl}$ buffer to a concentration of approximately $2 \times 10^{8}$ bacteria $/ \mathrm{ml}$. Equal volumes of bacteria and phage (titre $2 \times 10^{6}$ p.f.u./ $\mathrm{ml}$ ), prewarmed to $37^{\circ} \mathrm{C}$, were mixed and samples drawn after $\mathrm{I}, 2,4$ and $8 \mathrm{~min}$. For estimation of total attachment, samples were diluted in ice-cold $\mathrm{NaCl}$-supplemented tris- $\mathrm{HCl}$ buffer containing a few drops of $\mathrm{CHCl}_{3}$, and shaken vigorously on a Vortex mixer. The supernatant was titrated for free phage. For estimation of the number of infected bacteria, free phage and reversibly attached phage were neutralized by anti-phage serum. After $10 \mathrm{~min}$ incubation the mixtures were diluted and titrated for content of p.f.u. The a.r.c. was determined, up to $90 \%$ inactivation, according to the equation $\mathrm{d} P / \mathrm{d} t=K N P$, where $P$ is the number of unattached phages after time $t, N$ is the concentration of bacterial cells in the adsorption mixture and $K$ is the attachment rate constant.

Chemical methods. The LPS were hydrolysed in $1 \%(\mathrm{v} / \mathrm{v})$ aqueous acetic acid $\mathrm{pH} 3 \cdot 2$, at $100{ }^{\circ} \mathrm{C}$ for $60 \mathrm{~min}$. This procedure hydrolyses the acid-labile 2-keto-3-deoxyoctonate linkages between the core polysaccharide and the lipid $\mathrm{A}$, and results in a polysaccharide preparation with a much reduced lipid content. These polysaccharide preparations were used for the sugar and methylation analyses, which were performed as described by Hellerqvist et al. (1968).

\section{RESULTS}

\section{Determination of phage attachment rate constants}

The a.r.c. of phage $\mathrm{P} 22$ (having its receptor site in the $\mathrm{O}$ side-chain) and of phage $\mathrm{FO}$ (having its receptor site in the complete core) to the parent strains and their FOR mutants were measured to test whether the mutation to FOR had any effect on the attachment step. The a.r.c. for $\mathrm{P}_{22}$ to the parent FO-sensitive strain TV253 was $462 \times 10^{-11} \mathrm{ml} / \mathrm{min}$ (Table I). Attachment of the FO phage could not be demonstrated measuring unadsorbed phage, although the strain scores as FO-sensitive. This is due to the method, which is too insensitive when the rate of adsorption is low, i.e. a.r.c. $<5 \times 10^{-11} \mathrm{ml} / \mathrm{min}$. Estimation of the number of FO-infected cells, by neutralizing non-attached and reversibly attached FO phages by anti-FO antiserum, is a more sensitive method; the a.r.c. for TV253 (wild-type strain) was $0.08 \times 10^{-11} \mathrm{ml} / \mathrm{min}$. This value is, however, a minimal estimate since only a fraction of attached phages (for FO, 20 to $30 \%$ ) give rise to a lytic cycle (Lindberg, 1973), and the smooth FIRN strain TV253 plates FO with an efficiency of plating of only $10^{-1}$ to $10^{-2}$ as compared with the plating efficiency of FO on S. typhimurium LT2 strains.

The a.r.c. for $\mathrm{P}_{22}$ to the two FOR strains tested (SL4504 and SL4505), all originating from TV253, was 72 to $88 \%$ of the a.r.c. to the parent strain. None of the FOR strains could be shown to adsorb the FO phage, by measuring either the fraction of phage remaining nonattached or the fraction infecting cells. The FO phage did attach to strain SL45I2, an $r f c$ mutant of SL4505 which lacks the O repeat unit polymerase and therefore has only one repeating unit in the $\mathrm{O}$ chain. The a.r.c. was $\mathrm{I} 85 \times \mathrm{IO}^{-11} \mathrm{ml} / \mathrm{min}$. These data are in agreement 
Table I. Phage attachment rates to smooth, FOR and rff- strains, and yield of lipopolysaccharide

\begin{tabular}{|c|c|c|c|c|c|}
\hline \multirow[b]{2}{*}{ Strain } & \multirow[b]{2}{*}{ Character } & \multicolumn{2}{|c|}{$\begin{array}{l}10^{11} \times \text { Attachment rate constant } * \\
(\mathrm{ml} / \mathrm{min})\end{array}$} & \multicolumn{2}{|c|}{$\begin{array}{l}\text { Yield of LPS } \\
\text { (\% dry wt) }\end{array}$} \\
\hline & & $\mathrm{P}_{22}$ & FO & PhW & PCP \\
\hline TV253 & Smooth parent strain & 462 & $<5(0.08)$ & $3 \cdot 3$ & 0 \\
\hline SL45O4 & FOR & 333 & $<5\left(<10^{-5}\right)$ & $3 \cdot 5$ & 0 \\
\hline SL4505 & FOR & 358 & $<5\left(<10^{-5}\right)$ & $3 \cdot 9$ & 0 \\
\hline SL45 12 & SL4505 $r f c^{-}$mutant & 5 & I 85 & - & - \\
\hline
\end{tabular}

* The figures in parentheses represent the attachment rate by estimation of infected bacteria.

Table 2. Passive haemagglutination inhibition data for LPS extracted from smooth and FOR strains

LPS was extracted by the PhW procedure. Minimal inhibitory concentration* $(\mu \mathrm{g} \mathrm{LPS} / \mathrm{ml})$ for homologous systems representing:

\begin{tabular}{|c|c|c|c|c|c|c|c|c|c|c|c|}
\hline & $\mathrm{O}_{4}$ & $\mathrm{O}_{5}$ & $\mathrm{Or}_{2}$ & $\begin{array}{c}\text { SHI } 80 \\
\text { Ra }\end{array}$ & $\begin{array}{c}\mathrm{SL733} \\
\mathrm{Rb}_{3}\end{array}$ & $\begin{array}{c}\text { TVI6o } \\
\mathrm{Rb}_{2}\end{array}$ & $\begin{array}{c}\text { TVI } 48 \\
\mathrm{Rb}_{1}\end{array}$ & $\begin{array}{l}\mathrm{SL} 805 \\
\mathrm{Rc}\end{array}$ & $\begin{array}{c}\mathrm{SLIO}_{32} \\
\mathrm{Rd}_{2}\end{array}$ & $\begin{array}{c}\mathrm{SLI} I \mathrm{I} \text { I } \\
\mathrm{Rd}_{1}\end{array}$ & $\begin{array}{c}\text { SLIIO2 } \\
\text { Re }\end{array}$ \\
\hline TV253 & I & I & 128 & NI & NI & NI & NI & NI & NI & NI & NI \\
\hline SL45O4 & 2 & I & 64 & NI & NI & NI & NI & NI & NI & $\mathrm{NI}$ & NI \\
\hline SL4505 & I & 4 & 8 & NI & NI & NI & NI & NI & NI & NI & NI \\
\hline
\end{tabular}

* The minimal amount of LPS required to cause inhibition of a haemagglutination system of antiserum/ homologous LPS, as viewed by the naked eye. The antiserum dilution used represented 4 to 8 haemagglutinating units, where one haemagglutinating unit is the highest dilution of antiserum causing visible haemagglutination. For most systems homologous LPS inhibited the corresponding haemagglutination system in concentrations ranging from 0.4 to $4 \mu \mathrm{g} \mathrm{LPS} / \mathrm{ml}$ but for SLII8I and SLIIO2 $8 \mu \mathrm{g} \mathrm{LPS} / \mathrm{ml}$ was required.

NI, No inhibition was observed with $128 \mu \mathrm{g} \mathrm{LPS} / \mathrm{ml}$. The chemical symbols $\mathrm{Ra}, \mathrm{Rb}_{3}, \mathrm{Rb}_{2}$, etc., are as in Fig. $\mathrm{I}$.

with the hypothesis that in FOR strains the FO receptor, because of the mutation, is inaccessible to the phage.

\section{Extraction of LPS from FOR strains}

On the assumption that the FOR phenotype was the result of a mutation affecting synthesis of the core, with only a few of the core chains synthesized to completion and thus capped by $\mathrm{O}$ side-chains, it should be possible by using different extraction methods selectively to extract either LPS with only core chains or LPS with both O and core polysaccharide chains. The PCP method reportedly extracts only core LPS, i.e. LPS with a high lipid content, whereas the commonly used PhW method extracts both LPS with long hydrophilic $O$ polysaccharide chains and LPS with only a short core polysaccharide chain and which is therefore hydrophobic (Westphal \& Jann, 1965; Galanos et al. 1969). The amount of LPS extracted (expressed as a percentage of dry weight LPS per dry weight bacteria) by the PhW method from two of the FOR mutants was the same as from the smooth parent strain TV253 (Table I). No LPS could be extracted by the PCP method from strain TV253 or from the FOR mutants SL4504 and SL4505 (Table I). Thus the FOR strains were like the smooth parent strain with respect to the ability to extract LPS and the amount extracted. Passive haemagglutination inhibition experiments (Table 2), using systems of LPS and homologous antiserum representing the $\mathrm{O}_{4}, \mathrm{O}_{5}$ and $\mathrm{O}_{12} 2_{2}$ antigenic determinants of the smooth strains and all known rough mutants from chemotype $\mathrm{Ra}$ to $\mathrm{Re}$, revealed 
Table 3. Sugar composition of the phenol-water extracted lipopolysaccharide of the different strains analysed as their corresponding alditol acetates

The figures represent the molar ratios of the monosaccharides analysed as their corresponding alditol acetates.

$\begin{array}{llccccc}\text { Strain } & \text { Character } & \text { Mannose } & \text { Abequose* } & \text { Rhamnose } & \text { Galactose } & \text { Glucose } \\ \text { TV253 } & \text { FO sensitive } & \text { I.00 } & 0.65 & \text { I.04 } & \text { I.I5 } & 0.18 \\ \text { SL4504 } & \text { FOR } & 1.00 & 0.47 & \text { I.09 } & \text { I.05 } & 0.09 \\ \text { SL4505 } & \text { FOR } & \text { I.00 } & 0.85 & \text { I.09 } & \text { I.06 } & 0.29\end{array}$

* The amounts of abequose are underestimated, since no precautions were taken to prevent it from being destroyed during acid hydrolysis (Hellerqvist et al. 1968).

that the PhW-extracted LPS of strains TV253 (FO-sensitive), SL4504 and SL4505 (FOR) inhibited only the $\mathrm{O}_{4}$ and $\mathrm{O}_{5}$ systems. PhW-extracted LPS from all three strains inhibited the OI $2_{2}$ LPS/anti-OI $2_{2}$ antiserum system, the concentrations needed for inhibition varying from 8 to $128 \mu \mathrm{g} / \mathrm{ml}$ (Table 2). The OI $2_{2}$ specificity is determined by the glc $\mathrm{I}_{\alpha} \overrightarrow{4} \mathrm{gal}$ disaccharide unit of the repeating unit (Tinelli \& Staub, 1960). This antigen is subject to form variation (Stocker \& Mäkelä, 197I), which means that only some bacteria in a given strain make the $\mathrm{O} I 2_{2}$ antigen.

\section{Sugar analyses of the different LPS}

The sugar analyses were performed on polysaccharide fractions obtained after treatment of the LPS with aqueous acetic acid $\mathrm{pH} 3 \cdot 2$ for $60 \mathrm{~min}$ at $100^{\circ} \mathrm{C}$, which yields a polysaccharide with a diminished lipid content. The polysaccharide from each strain was hydrolysed in one step to give a mixture of monosaccharides which were analysed as alditol acetates by g.l.c. (Table 3). The different sugars were identified solely by their retention times and mass spectra. The sugars have, however, been fully characterized in previous investigations (Hellerqvist et al. 1968). Because no special precautions were taken during the acid hydrolysis to minimize the destruction of abequose, the values reported for this monosaccharide in Table 3 are underestimates. Previous investigations show, however, that abequose is equimolar to D-mannose and L-rhamnose (Hellerqvist et al. 1968). The figures show that, with the exception of abequose, the components of the $O$ repeating unit, i.e. D-mannose, L-rhamnose and D-galactose, are present in approximately equal amounts as expected. The fact that the amount of D-galactose, which is a component of the core as well, is virtually the same as the amounts of L-rhamnose and D-mannose indicates that per polysaccharide chain the core represents only a small part compared with the O chain in both FOR and parent strains. This interpretation is also strengthened by the fact that the amounts of D-glucose found are relatively small (Table 3 ). In LPS from smooth strains D-glucose is present both in the core (Fig. I) and (in some strains) as a terminal non-reducing branch on C-4 of $\mathrm{D}$-galactose in the $\mathrm{O}$ side-chain, giving the bacteria $\mathrm{O}_{2} 2_{2}$ specificity (Table 2). Small amounts of a heptose were found in the chromatograms of all analysed polysaccharides but are not included in Table 2. Thus the LPS from the FOR strains have as much O-specific sugars as that from the parent FO-sensitive strain. As the LPS yields are the same, the sugar analyses did not reveal any differences between LPS from FOR and from FO-sensitive strains.

\section{Methylation analysis of the lipopolysaccharides}

The polysaccharide was methylated with methyl-sulphinyl sodium and methyl iodide in methyl sulphoxide, and thereafter hydrolysed to a mixture of methylated sugars. These were analysed as their alditol acetates by gas-liquid chromatography and mass spectrometry 


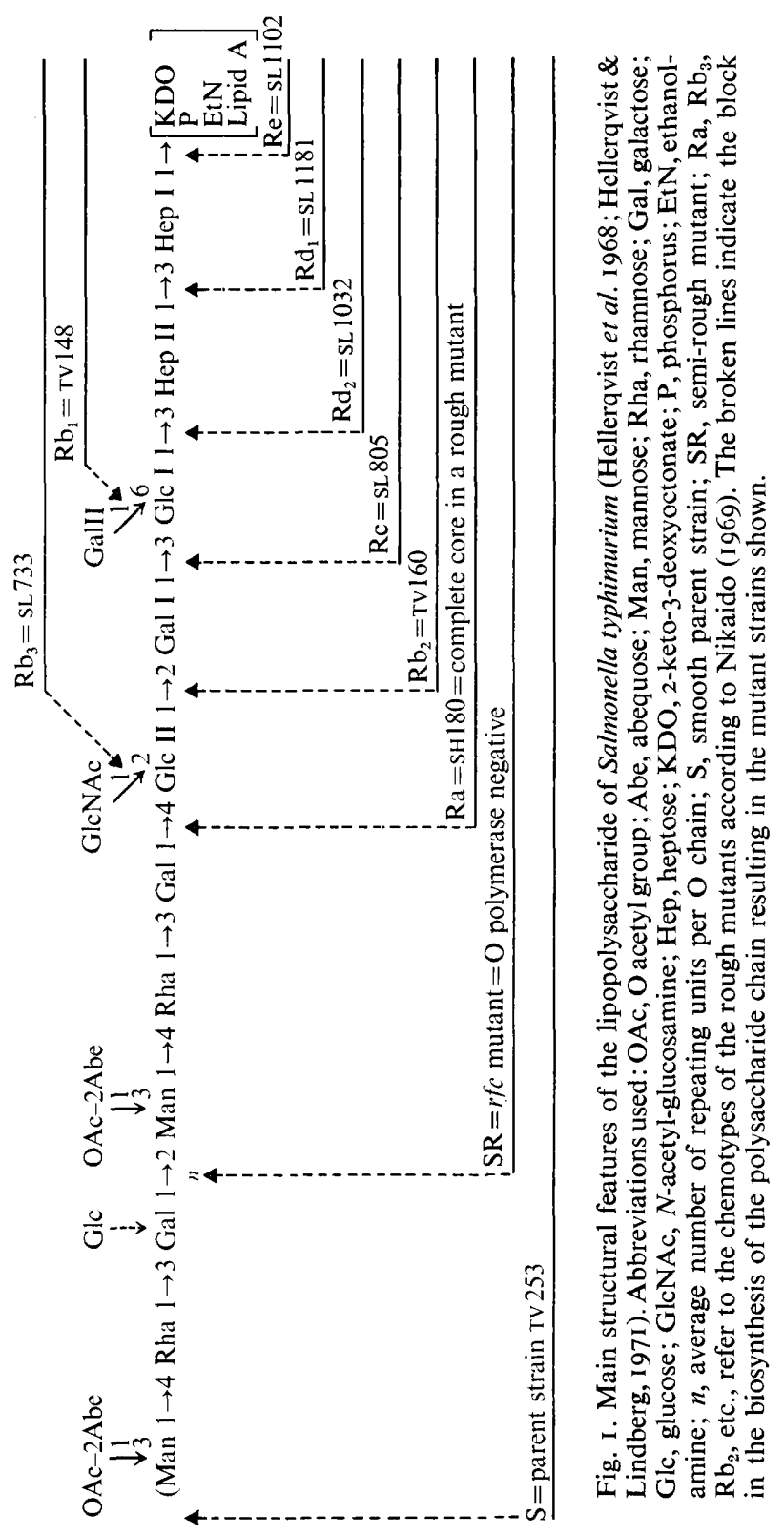


Table 4. Methyl ethers from the hydrolysate of methylated lipopolysaccharides

\begin{tabular}{|c|c|c|c|c|c|}
\hline \multirow[b]{2}{*}{ Methyl ether } & \multirow[b]{2}{*}{ Source(s) in LPS* } & \multirow[b]{2}{*}{$\begin{array}{c}\text { Retention } \\
\text { time } †\end{array}$} & \multicolumn{3}{|c|}{$\begin{array}{c}\text { Molar proportions of } \\
\text { methylated sugars } \ddagger\end{array}$} \\
\hline & & & $\begin{array}{l}\text { TV253 } \\
\text { FO-sensitive }\end{array}$ & $\begin{array}{c}\text { SL45O4 } \\
\text { FOR }\end{array}$ & $\begin{array}{c}\text { SL4505 } \\
\text { FOR }\end{array}$ \\
\hline 2,4 -Di- $O$-methylabequose & $O$ repeating unit & 0.32 & 15.9 & 13.9 & I $6 \cdot 8$ \\
\hline 2,3-Di- $O$-methyl-L-rhamnose & $O$ repeating unit & 0.98 & $29 \cdot 0$ & $26 \cdot I$ & $22 \cdot 9$ \\
\hline $2,3,4,6$-Tetra- $O$-methyl-D-glucose & $\begin{array}{l}\text { Branch on O repeating unit } \\
\text { or non-substituted GlcI } \\
\text { or GlcII of core }\end{array}$ & $1 \cdot 00$ & $\mathrm{I} \cdot 5$ & $1 \cdot 7$ & $7 \cdot 1$ \\
\hline 2,4,6-Tri- $O$-methyl-D-mannose & Terminal $O$ repeating unit & $2 \cdot 08$ & 0.8 & $I \cdot I$ & 0.7 \\
\hline 2,4,6-Tri-O-methyl-D-galactose & $\mathrm{O}$ repeating unit & $2 \cdot 29$ & $23 \cdot 5$ & $25 \cdot 5$ & $16 \cdot 5$ \\
\hline 4,6-Di- $O$-methyl-D-mannose & Internal $\mathrm{O}$ repeating unit & $3 \cdot 29$ & $26 \cdot 8$ & $27 \cdot 5$ & $23 \cdot 9$ \\
\hline 2,6-Di- $O$-methyl-D-galactose & $\begin{array}{l}\text { O repeating unit with } \\
\text { Glc-substitute }\end{array}$ & $3 \cdot 65$ & 0.9 & $\mathrm{I} \cdot 7$ & $7 \cdot \mathrm{I}$ \\
\hline
\end{tabular}

* The sugar residue in the polysaccharide chain of the LPS corresponding to the methyl ether is indicated using the abbreviations in Fig. I.

$\dagger$ Relative to $2,3,4,6$-tetra- $O$-methyl-D-glucose taken as $\mathrm{I} \cdot 00$.

\pm Given relative to that of 2,3 -di- $O$-methyl-L-rhamnose, assumed to be the same as the percentage of L-rhamnose in the original lipopolysaccharide.

(Table 4). The relative proportions of D-mannose, abequose, L-rhamnose, D-galactose and $D$-glucose, as calculated from the methylation analyses, are in reasonably good agreement with the sugar analyses given in Table 3 .

The parent strain TV253 has an $\mathrm{O}$ side-chain which is a linear polysaccharide of polymerized repeating units (Fig. I). The average number of repeating units per $\mathrm{O}$ chain, calculated from the ratio of 2,4,6-tri- $O$-methyl-D-mannose (representing the mannose in the terminal repeating unit) to 4,6 -di- $O$-methyl-D-mannose (representing the mannose residues in internal repeating units) was 35 . The relative amounts of methyl ethers derived from sugar residues of the core were small, often less than $0.5 \%$ of the methyl ethers found. Since the quantitative estimates of such small amounts are less accurate these ethers were not included in Table 4. Calculations of the ratios for the LPS from the FOR strains, SL4504 and SL4505, show the average number of repeating units per $O$ chain to be 26 and 35, respectively (Table 4). The OI $2_{2}$ antigenic specificity is determined by D-glucose linked L- $\alpha-I, 4$ to the D-galactose residue of the repeating unit (Tinelli \& Staub, 1960). From comparison of the amounts of 2,6-di- $O$-methyl-D-galactose (representing a glucose-substituted D-galactose residue in the $\mathrm{O}$ repeating unit) with those of 2,4,6-tri- $O$-methyl-D-galactose (representing nonsubstituted D-galactose residues) it was calculated that about $4 \%$ of the repeating units in TV253 carried a 1,4 -linked D-glucose (Table 4 ). The corresponding figures for SL4504 and SL4505 were 6 and $33 \%$, respectively.

\section{DISCUSSION}

The FOR strains differ from their smooth parent strains primarily by being resistant to the FO phage, for in cultural and serological properties the FOR mutants were almost identical to the smooth strains (MacPhee et al. 1975). This investigation was performed in order to try to analyse whether there were either qualitative or quantitative differences between LPS from FOR mutants and LPS from the parent strain, even if these could not be 
demonstrated in the qualitative assays. The amount of LPS that could be extracted by the $\mathrm{PhW}$ method was approximately the same for the two FOR mutants (SL4504 and SL4505) as it was for their parent strain (TV253). No LPS could be extracted from any of these strains by the PCP method.

In passive haemagglutination inhibition both FOR strains displayed smooth $\mathrm{O}_{4}, \mathrm{O}_{5}$ and $\mathrm{OI} 2_{2}$ antigenic activities. None of the LPS displayed significant activity in any of the "corespecific' haemagglutination systems.

The rate of attachment of phage $\mathrm{P}_{22}$, with its receptor in the $\mathrm{O}$ side-chain (Lindberg, 1973), to FOR strains was virtually the same as to the parent strain. Again this suggests that the amount of O chains in the FOR mutants is the same, or almost the same, as in the parent strain. As expected, the rate of attachment of phage FO (which uses the complete core LPS as receptor (Lindberg, I973)) to the parent strain was low (Table I). No attachment to FOR mutants could be demonstrated. The observation that FO attached to strain SL45I2 (O polymerase-negative mutant of SL4505) at a relatively high rate showed that a considerable number of core stubs in strain SL4505 are completed and probably carry the $\mathrm{O}$ chains.

One hypothesis to explain the inability of FOR strains to adsorb FO phage is that the $O$ chains are longer because the number of cores is reduced. The longer $O$ chains would interfere with and prevent the attachment of the FO phage to its receptor. The methylation analysis revealed, however, that the average number of repeating units per $O$ chain was about the same in TV253 as in the FOR mutants SL4504 and SL4505, being 35, 26 and 35, respectively (Table 3). Although we have no means of estimating the distribution of the length of the $\mathrm{O}$ chains, these data suggest that interference with attachment because of long $\mathrm{O}$ chains is an unlikely hypothesis.

Another hypothesis is that smooth strains are FO-sensitive because not all complete cores are capped by $\mathrm{O}$ chains. In FOR strains, if there is a mutation in the biosynthesis of the core, fewer complete cores would be synthesized. Since the amount of LPS and the average length of $O$ chains seems to be the same in the FOR mutants as in the parent strain, fewer complete cores would be left uncapped and available for the FO phage in the FOR mutants. The core represents, however, only a minor part of a polysaccharide chain where there are 30 repeating units. The amounts of methyl ethers derived from sugar residues of the core were also too small to be determined with accuracy. The data of Table 3 therefore do not test the hypothesis that FOR strains have fewer completed cores. Haemagglutination inhibition experiments did not reveal the presence of unsubstituted cores in the PhW-extracted LPS of the smooth parent strain TV253 (Table 2). This is probably because the method was not sensitive enough, since immunization of rabbits with smooth Salmonella strains gave low, but significant, titres against the complete core (Schlecht, Böhlck \& Westphal, I97I).

The experiments described in this paper, though they have disproved one hypothesis, have not clarified why the FOR mutants do not adsorb FO whereas the smooth parent strain does. It is obvious that the methods used are not sensitive enough to show the differences that we think exist in the polysaccharide part of the LPS. We are presently investigating the properties of $r f b$ derivatives of FOR strains which are devoid of O chains, to see if the differences which most probably exist in the core can be amplified in our analytical systems when the bulk of $\mathrm{O}$ chain material is not present.

One interesting observation was made. MacPhee et al. (1975) found that the FOR strain SL4504 was still virulent for mice, whereas SL4505 was not. The amount of LPS and the average length of $\mathrm{O}$ side-chain was virtually the same for the two FOR strains. The reason for the difference in virulence may still be found in the structure of the LPS, i.e. the defect in SL4505 might affect an earlier step in the biosynthesis of the core than in SL4504, making it 
more susceptible to complement, phagocytosis, etc. Nevertheless, the data indicate that the presence of 'almost normal or normal' amounts of $O$ chains, of normal number of repeating units per O chain and of LPS in the outer membrane of $S$. typhimurium are not sufficient for virulence.

The skilled technical assistance of Ms M. Thorén and Ms G. Allestam is gratefully acknowledged. This work was supported by NIH Postdoctoral Fellowship No. Fo5 TW 1912 (to A.A.L.), by the Swedish Medical Research Council (grant No. 40X-656) and a USPHS research grant, AI207I68, from The National Institute of Allergy and Infectious Diseases.

\section{REFERENCES}

Galanos, C., Lüderitz, O. \& Westphal, O. (I969). A new method for the extraction of R lipopolysaccharides. European Journal of Biochemistry 9, 245-249.

Hellerqvist, C. G. \& LindBerg, A. A. ( 1971). Structural studies of the common core polysaccharide of the cell-wall lipopolysaccharide from Salmonella typhimurium. Carbohydrate Research 16, 39-48.

Hellerovist, C. G., Lindberg, B., Svensson, S., Holme, T. \& Lindberg, A. A. (1968). Structural studies on the O-specific side-chains of the cell-wall lipopolysaccharide from Salmonella typhimurium 395MS. Carbohydrate Research 8, 43-55.

Kauffmann, F. (I966). The Bacteriology of Enterobacteriaceae. Copenhagen: Munksgaard.

LiNDBERG, A. A. (1973). Bacteriophage receptors. Annual Review of Microbiology 27, 205-24I.

LiNDBERG, A. A. \& Holme, T. (1968). Immunochemical studies on cell-wall polysaccharide of rough mutants of Salmonella typhimurium. Journal of General Microbiology 52, 55-65.

LiNDBERG, A. A. \& Holme, T. (1972). Evaluation of some extraction methods for the preparation of bacterial lipopolysaccharides for structural analysis. Acta pathologica microbiologica scandinavica B 8o, 75I-759.

MacPhee, D. G., Krishnapillai, V., Roantree, R. J. \& Stocker, B. A. D. (1975). Mutations in Salmonella typhimurium conferring resistance to Felix $\mathrm{O}$ phage without loss of smooth character. Journal of General Microbiology 87, I-IO.

NIKAIDO, H. (1969). Biosynthesis of cell-wall lipopolysaccharide in Gram-negative enteric bacteria. Advances in Enzymology 31, 77-II 2.

SCHLECHT, S., BöHLCK, I. \& WeStPHAL, O. (197I). Nachweis von Antikörpern gegen Salmonella-R-Antigene in Salmonella-O-Antiseren. Zentralblatt fiur Bakteriologie, Parasitenkunde, Infektionskrankheiten und Hygiene (Abteilung I) 216, 472-482.

StOcker, B. A. D. \& MäKelä, P. H. (1971). Microbial Toxins, vol. 4, pp. 369-438. New York: Academic Press.

Tinelli, R. \& Staub, A. M. (1960). Analyse de l'antigène $\mathrm{O}_{12}$ du tableau de Kauffmann-White. Bulletin de la Société chemie biologique 42, 583-599.

WestPhal, O. \& JANN, K. (I965). Methods in Carbohydrate Chemistry, vol. 5, pp. 83-9i. New York: Academic Press.

Wilkinson, R. G., Gemski, P., Jun. \& Stocker, B. A. D. (1972). Non-smooth mutants of Salmonella typhimurium: differentiation by phage sensitivity and genetic mapping. Journal of General Microbiology 7o, 527-554. 